\title{
EXPERIMENTS ON SEX RECOGNITION AND THE PROBLEM OF SEXUAL SELECTION IN DROSOPHILA
}

\section{A. H. STURTEVANT \\ Columbia Lniversity}

Much has been written on the subject of sexual selection since Darwin first developed the theory, and many remarkable observations have been recorded. There has, however, been very little experimental work in this field. Darwin and those who have followed him have obtained much of their evidence from the insects, and within this group some of the most striking cases of elaborate mating habits have been reported in the Diptera, and here too there is to be found a most remarkable arrayt of secondary sexual characters. Perhaps the most extreme case is that of the Elaphomyia described by Wallace, in which the male has long, hornlike processes arising from his head, which are absent in the female. The families of Platypezidae, Dolichopodidae, and Empididac are especially rich in secondary sexual characters, which occur in the legs, wings, antennae, face, or other parts. In the two latter families some very curious observations on mating habits have been recorded (see especially Poulton's account ('13) of Hamm's work on Empididae).'

Some of the best experimental evidence in favor of sexual selection is that obtained by Lutz (1911), who worked with an abnormal wing venation in Drosophila ampelophila which he found to be strongly selected against. To Dr. Lutz is due the suggestion that the mutants in this fly obtained by Morgan would form excellent material for the study of the problem. The method of some of the experiments was also suggested by Lutz. I took up the matter at the suggestion of Professor Morgan, to whom I am greatly indebted for most of the material and for his encouragement and criticisms. Several discussions of the matter with Dr. Lutz have also been very helpful. Some

'I have myself observed courtshp in a few Dolichopodidae and in a number of other Diptera. These observations will be published in full later. 
of the work was done at the Cold Spring Harbor Laboratory in the summer of 1911, and I wish to express my appreciation of the interest in the experiment shown by Dr. C. B. Davenport at that time.

\section{COURTSHIP AND MATING}

- Most of my observations on courtship in Drosophila have been made upon $D$. ampelophila Loew. In general the process is very similar in $D$. busckii Coq., but differs in several respects in D. amoena Loew, D. repleta Woll., and D. funebris Fabr. The first and most noticeable act in courtship occurs when the male, being near the female, extends one wing at about right angles to his body, and vibrates it for a few seconds. The wing is then returned to the normal position and the process is repeated, usually with the other wing. But between times there is a scissors-like movement of the wings repeated several times. This vibrating of the wings is often repeated many times, and may be done in any position relative to the female, though the male a'ways faces her. Usually, in fact, he swings quickly around her in a semicircle once or oftener during the process. Soon the male begins to protrude his genitalia and, if the female remains quiet, to lick her posterior end Some white matter now protrudes from her ovipositor, and other males in the same vial are usually observed to become excited now and begin courting; indicating odor as a cause of sexual excitement. If the female runs or flies away the male is excited, moves his wings jerkily, and walks around rapidly, but seems unable to follow the female accurately or to locate her quickly. The penis is. directed forward by bending up the abdomen underneath, towards the thorax, and is jerked toward the female (the male always standing facing her at this stage), but not always toward her genitalia, as I have seen it strike her in the eye. ${ }^{2}$ If it does strike the mark the male mounts on the female's back, between her wings. Mounting never takes place until after the actual copulation has occurred, in which respect Drosophila differs from some related files (e.g., Muscidae, Anthomyidae, Sepsidae, Borboridae, and Ephydridae, so far as my observations go). In these forms the male flies and lights on the female,

\footnotetext{
${ }^{2}$ The male in this case, however, had white eyes, and so was perhaps blind, Normally the aim is accurate.
} 
after which copulation may or may not take place, probably depending upon the way the female responds.

Berlese ('02) and Hewett ('08) find that in the house fly the final step in copulation is taken by the female, which inserts the ovipositor into the genital opening of the male. I have not been able to verify this for Drosophila, but it is probably true here also. In Drosophila, as in some other related flies (I have examined a few Anthomyids and Sepsis violacea), the ovipositor enters the male opening, instead of the penis entering the female duct. But I cannot state positively that the female inserts it instead of the male drawing it in by means of his genital armature. In any case, it is certain that the female is not entirely a passive agent. The time required for copulation to take place depends largely upon whether she stands quietly and allows the male to pair, or moves away when he begins to court. In the latter case very active males have been seen to pair while the female was walking away, but this is exceptional Occasionally a female seems to frighten off a male by spreading her wings $\tilde{s}$ and moving quickly toward him. ${ }^{3}$ When this happens he moves off, and does not so far as I have seen, then pair with that female, although she has been known to pair with another male within a few minutes afterward. That this is really a threat on the part of the female seems likely from observations of fighting between males. If two males are courting the same female they often grow very excited, especially if she is unwilling to stay quiet. In such cases they may sometimes be seen to suread their wings, run at each other, and apparently butt heads. One of them soon gives up and runs away. If the other then runs at him again within the next few minutes he usually makes off without showing fight.

The time occupied by the process of courtship varies greatly with the age and condition of the flies and with the temperature. Copulation may occur within a few seconds after the flies are put together, with little preliminary courtship. While experimenting with flies about 3 or 4 days old, which had never been allowed to pair, I have found that 20 minutes or a little less is about the average length of time before copulation occurs. The flies may remain in copula for only a few seconds, but so far

\footnotetext{
${ }^{3}$ Compare Howard's ('02, pp. 141 and 145) accounts of Asilid and Empidid fles eating males which were courting them.
} 
as my observation goes this occurs only after a prolonged courtship in which the female has seemed unwilling to mate, and is, I think, due to the male not getting a good hold. I do not know whether or not such pairings are successful. Ordinarily copulation lasts about 20 minutes ${ }^{4}$

\section{EXPERIMENTS ON OTHER INSECTS}

There is a considerable body of evidence relating to the question of sex recognition in the Arthropods. A short review of the subject and a bibliography are given by Chidester ('11), so I shall confine myself here to the evidence dealing with insects. There is evidence from several groups of insects, but most of it points the same way. Sex recognition at a distance is by smell, but the actual process of copulation depends upon the sense of touch.

In the Orthoptera, Stockard ('OS) has observed the male walking stick to pair with the detached abdomen of a female which was fastened to a stick with wires for legs.

In Coleoptera, Féré ('98) finds"that male cockchafers do not pair if the antennae are removed. Males will sometimes pair with males, prov ded the latter have just paired with females, or have been artificially impregnated with female juices.

Mast ('12) shows that in the firefly the males find the females by means of the flashing lights, signals being made by both sexes. Tower ('06) reports that in Leptinotarsa males normally never try to actually copulate with males, but that if the antennae are removed or painted with shellac they will try to pair with any individual they happen to touch. If this individual is a female pairing will occur. If the abdomens of females are removed the males are attracted by them, though not by the wings, head and thorax. Females with their abdomens coated with shellac are not attractive to the males.

Féré ('98a) found that in the silkworm moth males will parr with other males, which have not been given a chance to get the female odor, if the latter males are sluggish, as after removal of the antennae. Males without anter..ae will copulate. Kel$\operatorname{logg}(07)$ has since reported that $m_{\text {ales }}$ without antennae find the females only by chance, while. normal ma'es go straight to

4 In 20 cases the duration of copulation was timed with the following result (minutes): $\frac{1}{2}, 5,16,17,18,18,19,20,21.21,21.21,22,22,23,24,25,2627$. 33 , 
them. If one antenna be remored the male travels in a circular path instead of going toward the female. If a male without antennae happens to touch a female he immediately shows strong sexual excitement, such as normal males show when brought near females. Scent glands on the abdomen of the female were shown to be the seat of the olfactory attraction, for when the abdomens were removed males were attracted by them and not by the rest of the female. Blackening the eyes produced no change in the behavior.

Nayer (1900) performed numerous experiments on the moth Callosamia Promcthea. He showed that it is odor that attracts the males, and that this odor comes from the abdomen of the female. Interchanging of wings indicated that the marked sexual dimorphism in color, which occurs in this species, has no selective value.

Firkland (1896) showed that in the Gypsy moth odor is again the main element concerned, but the wings of the female, as well as her abdomen, have an exciting odor. Mayer and Soule (1906) tried experiments on this form, which they supposed indicated that normal females discriminated against males without wings. I find. by applying Yule's (1911) formula for the standard error of the difference, that the difference between the per cent of times winged males paired without resistance and the per cent that wingless males paired without resistance (the measure of sexual selection used by these authors) is almost exactly three times the standard error. This means that the result is not conclusive. Mayer and Soule blinded females and found this apparent discrimation against wingless males to disappear, but the per cent of resistance dropped, as a whole, from $46 \%$ in the normal females to $27 \%$ in the blinded ones. This may mean that the blinded ones were too greatly disturbed by the blinding to pay much attention to what male mated with them. While I am inclined to suspect that there is some odor connected with the male's wings, still, as stated above, it is not certain that any effect at all is produced by removing the wings of the male. Further evidence against the importance of sight is furnished by the fact that females did not discriminate against males with wings painted in unusual colors.

\footnotetext{
"I have not seen this paper, but make the statement on the authority of Mayer and Soule (1906).
} 
Federley (1911) gives evidence indicating that odor is a strong sexual stimulator in the moth Pygaera, and may even cause males to attempt to pair with the bars of the cage in which they are confined. Entomological literature contains many accounts of the remarkable ability of male moths to locate females though smell. A few of the more striking cases are given by Washburn ('09, pp. 87 and 88.)

\section{SEX RECOGNITION IN DROSOPHILA}

It was noted above that when an egg protrudes from the ovipositor of a female any males in the same bottle usually become excited and begin courting. When a female is killed eggs are likely to protrude, and males are often seen vigorously courting females which have been freshly killed, even though the killing agent were so strong smelling a substance as ether. In such cases it is the posterior end of the abdomen which seems to be the chief focus of attraction. The attraction may last for at least 30 minutes after death, and probably longer. I have not as yet been able to cause males to copulate with dead females, probably because the female normally takes an active part, as indicated above.

If a male which has just paired is placed with a male which has been isolated from females for several days he may be courted by that male, though this is not frequent. If two males are kept in solitary confinement for four or five days and are then put together they often court each other, in one case even the doubling up of the abdomen being seen, and the wing movement (not fighting) being almost invariably observed. Such mutual courtship between males has not been seen under other conditions, but a dead male which had not been with females for two days before killing has been seen to be courted by other males. This courting, however, seems more likely to occur when juices from female ahdomens are put on the dead males. In Psychoda sp. courtship of males by males seems to be very frequent, and often copulation is attempted. The genitalia even become attached, and stay so for several seconds. Males have been seen to mount males in Fucellia marina, Sepsis violacea, and Sarcophaga sp.

In order to test what part is played by the female juices. 
mentioned above I placed some on bits of filter paper and put these in the same vial with males. The males paid no attention to the paper, and showed no signs of excitement, though that they were sexually ripe was shown by the fact that they courted and paired with females when they were put in with them. This experiment has been repeated several times with the same result When a female is thoroughly crushed and the remains heaped up in a little pile the males will sometimes court slightly, but as a general rule, the more mashed the female is, the less excited the males become. No great importance is to be placed upon this latter experiment, as the result is complicated by the presence of so many other body juices. This objection, however, will hardly hold in the case of the filter paper impregnated with female juices. The objection that not enough odor was present may perhaps be justifiable in that case. But neither of these objections would seem to apply to the following experiment. Two females were placed in a small, dark, cloth bag and this was put in a vial with a few males. The males were close to the females, which they could not see or touch, but should be able to smell. This experiment was done three times and in no case did the males show any signs of sexual excitement, though in all three cases they did court immediately afterwards when given females in the usual way.

It has been shown by Barrows ('07) that the sense organs for smell in Drosophila, insofar as one may judge from reactions to food substances, are located in the terminal antennal joints. For this reason I was led to perform the following experiments, in an effort to determine the part played by the sense of smell in courtship and copulation.

The antennae were removed from several males, ${ }^{6}$ which were after several days placed with virgin females. Such males are very sluggish, and it was therefore not surprising that no courtship was observed. However, one such male was found copulating, and at least three of them left offspring after the operation. One of the three had white eyes, and was therefore probably also blind. Courtship has been observed in two males from which the antennal aristae had been removed. A normal male has been seen copulating with a female from which the antennae

\footnotetext{
- I have found that antennae may easily be removed without using the complex method described by Barrows, if the operation be performed on very young fles.
} 
had been removed, and this pairing resulted in the production of offspring.

The above experiments failed to give any evidence demonstrating that smell alone can cause males to show signs of courtship. Another series of experiments, now to be described, has indicated, however, that smell may be a secondary factor in causing sexual excitement. Males and virgin females were isolated for three or four days and were then placed, in pairs, in clean vials. The length of time before copulation occurred was recorded; and, after it had taken place, the flies were removed and a new pair was placed in the same vial. The only difference between the two sets was that one lot was in clean vials, the other was in vials in which copulation had just occurred. In these experiments an equal number of each sort was done on each day (placing a third pair in some vials whon necessary in order to get an equal number), and all flies used on a given day were as nearly the same age and size.as practicable, and were from the same culture. Table I gives the result of the experiments. It shows that in the first five or six minutes

TABLE I

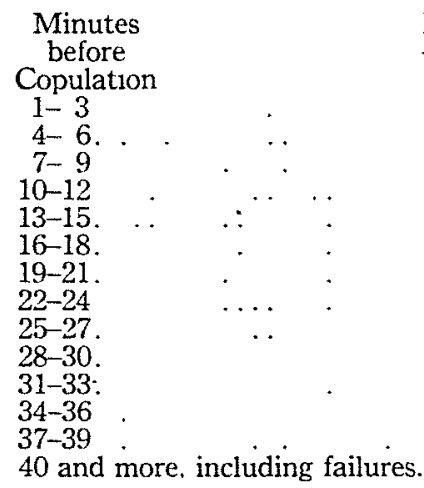

Number of times observed

$\begin{array}{rc}\text { 1st pair } & \text { 2nd pair } \\ 13 & 22 \\ 12 & 22 \\ 5 & 7 \\ 7 & 6 \\ 11 & 2 \\ 7 & 5 \\ 8 & 5 \\ 4 & 3 \\ 5 & 3 \\ 2 & 1 \\ 7 & 1 \\ 2 & 2 \\ 0 & 2 \\ 24 & 25\end{array}$

the flies in the used vials are more likely to copulate than are those in the clean vials; between ten and twenty minutes there are more copulations in the clean vials, and after that the two series are parallel. Apparently there are a certain number of pairs that are nearly ready to mate, and these will mate more quickly if another copulation has just occurred in the same vial. But if much courtship is to be required before copu- 
tation, then the effect of smell is negligible. It is not clear from these results whether the effect is produced upon the males, the females, or both.

In order to test whether sight is the sense which stimulates the male I carried out the following experiment. Two vials having the same bore were filled with cotton up to about three centimeters from the mouths, and then placed with their mouths together. A thin glass cover-slip was then placed between them, and a male fly was placed in one vial, a female in the other These flies had been isolated for several days, and were sexua1ly ripe. The male could see the female, but could not touch or smell her. Once or twice they met "head on "with only the cover-slip between them, but the male showed no signs of recognition. After thirty minutes the female was let in the vial containing the male; and the vials were left in position. $\mathrm{He}$ courted her within two minutes, and paired in five minutes. The experiment was repeated with the same result, except that copulation now occurred in three minutes after putting the flies together.

It is also evident that sight is not necessary for pairing from the facts that Drosophila breeds freely in the dark (see Payne, '11), and that pure stock of white-eyed flies (which may be blind) has been kept for many generations.

In Fucellia marina and in Musca domestica males seem to see their mates from some distance and fly directly to them, lighting on the back of the mate. Here sight would seem to play considerable part, and in Fucellia still more convincing evidence was obtained from observation of violent courtship of a fly which was separated by thick glass from the courter. Not only did this male court the other fly, but when she walked around rather rapidly, he very accurately followed her on the other side of the glass. This has been observed twice.

Since the wings play such a conspicuous part in courtship I was led to try the effect of cutting them off. Two males of the same age were used, the wings of one being cut off at the base. These were kept in the same vial for several days, and then placed with a virgin female several days old. The vial was then watched until copulation took place. This has been done 125 times, using different individuals each time. The normal male paired 72 times, the clipped male 53 times. As 
in all the similar experiments here reported care was taken to have the competing flies as nearly the same age and size as possible. The result indicates that there is very slight, if any, selection against the clipped males. It seemed possible that courtship made the female ready to copulate, but that she would then mate with either male. To test this hypothesis another series of experiments was carried out. A single pair of flies was placed in each vial, using each day an equal number of normal and of clipped males. The length of time before copulation was recorded in each case. A preliminary account of this experiment has been published by Morgan ('13); but the data used there have been discarded, since two serious sources of error had not then been recognized. It was not realized that the time before copulation might be influenced by a previous copulation having occurred in the same vial; and sufficient precautions against drying were not taken - a very important factor. A new series of experiments, in which these points were controlled, gave the results shown in table II. As a matter of fact, however, these data are very similar to the discarded series.

TABLE II

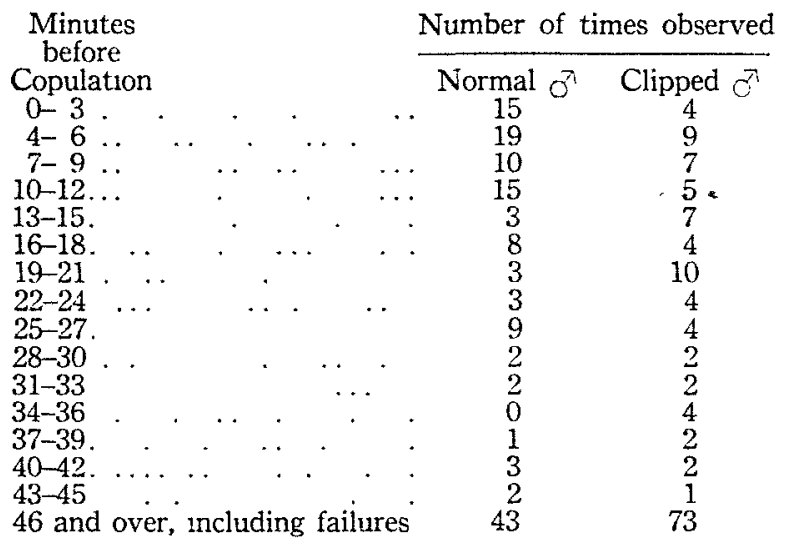

This table seems to justify the suspicion that led to the experiment. Had the females discriminated against the clipped males to the extent shown above when both kinds were present, the normal males would certainly have appeared at a greater advantage. That the result was not due to less activity on the part of the clipped males is indicated both by the contests described above 
and by the following observations. In some of the experiments recorded in table II the number of minutes before courtship began was observed. Table III indicates that the clipped males began courting as quickly as did the normals.

TABLE HI

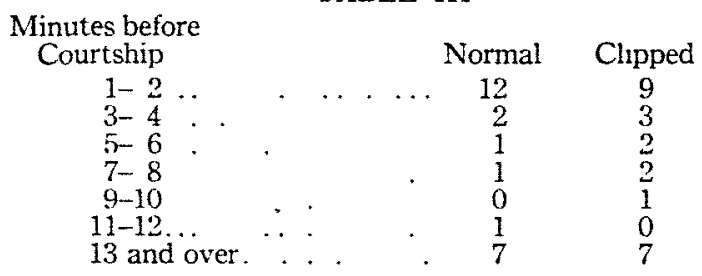

From these experiments it seems certain that the wings are of value in courtship: but the effect probably is to produce sexual excitement in the female, rather than to cause her to select a male that uses his wings. No "choice" is involved; but, as pointed out by Watson ('14, p. 173), the effect, in nature, would be strongly in favor of the normal male.

It seems probable that touch is of considerable importance in the sexual process, and all my observations are consistent with that view, but I have no direct experimental evidence to that effect. It is not possible to get evidence from Drosophila such as Kellogg obtained from Bombyx, because the flies are more active, and less easily sexually excited, than is the silkworm moth.

Two kinds of experiments have been carried out in an effort to find out what part of the body is responsible for causing sexual excitement. A female without an abdomen, but alive and active, was placed with males that had been isolated from other females for four days. She was vigorously courted.

Three gynandromorphs have been tested to determine their sexual behavior. None showed any certain indications of male behavior, but all were vigorously courted by males. Of these three gynandromorphs the external characters were as follows. (A) All female, except one side of the head, which was male; (B) female on one side of the whole body, male on the other side: (C) female, except the genitalia, which were male. It is doubtful what conclusion, if any, is to be drawn from these few observations. 


\section{SEXUAL SELECTION-ARTIFICIAL ABNORMALITIES}

The male of Drosophila ampelophila bears a small comb on his front metatarsi, a secondary sexual character not found in most species of the genus. ' Lutz ('11) has shown that the removal of this comb has no effect upon the availability of males for copulation. That is, the females were not influenced by the sex-comb in their choice of mates.

It sometimes seems to be difficult for the male to get the wings of the female out of his way so that he can mount her. For this reason I carried out an experiment the converse of one recorded above; using two virgin females of the same age, one with normal wings, the other with wings removed. These were put with a normal male. In 52 successful trials the normal female was paired with 25 times, the clipped one 27 Again it would seem as though clipping the wings has very little if any effect.

\section{SEXUAL SELECTION-MUTANTS}

Lutz ('11) found that certain slight abnormalities in wring venation were selected against both by normal and abnormal flies of both sexes. The abnormal flies were not noticeably different from the normals in behavior, so that it seems quite unlikely that the results were due to a difference in the activity of the two types. Moreover, if, let us say, the normal male was more active than the abnormal, so that he would be more likely to pair first, it would seem that the normal.female would not be so easily paired with as the abnormal; or vice versa, if we suppose the abnormal female to be less active and therefore more likely to be paired with, it is hard to see why the abnormal male should be at a disadvantage. Further evidence bearing out this view of the effect of differences in activity will be given below Lutz suggested that it seems unlikely that sight could have any influence, and that perhaps there is some unpleasant smell correlated with the abnormality, this being the basis of selection.

I have conducted a series of experiments upon some of Morgan's Drosophila mutants, in an effort to find if there was any selective mating in connection with them. The following mutants were used:

${ }^{7}$ So far as my observation goes it is present only in $D$. ampelophila, D. conjusa, D. obscura, and three or four undescribed species. 
(1) White eyes. This form was first described by Morgan ('10). There is no color in the eye. This probably means that the fly is blind, and it has often been observed to be less strongly phototactic than the wild fly. White eyed flies are also less active and vigorous than normals.

(2) Yellow body color Described by Morgan ('11). The whole body of this fly is lighter than that of the normals, and there is a distinct yellow color to the wings. Sight seems to be normal, but again the flies are not so active as are the normals.

(3) Curved wings. The main interest of this form in this connection is that the wings are always held extended, in some. what the same position as that of the courting males. The flies are perhaps a little less active than the normals

(4) Vermilion eyes. Described first by Morgan ('11a). These flies differ from the normals in that the eyes are of a brighter and less intense red Their vigor and activity is very little, if at all, inferior to that of the normals

Some of the flies used had yellow bodies and white eyes, and in one experiment a few vermilion eyed yellow black colored females were used. This latter combination was at the time considered one of the weakest stocks in the laboratory, and was used for that reason.

The method of the experiment was as described above for the wing clipping experment. For instance, a white eyed female would be given her choice between a red male and a white one of the same age and size. Then the experimenter simply watched until pairing was seen, and the flies were then thrown away. The following table (IV) gives the results obtained.

TABLE IV

\begin{tabular}{|c|c|c|}
\hline \multicolumn{3}{|c|}{ Red vs. white eyes. (Normal body color.) } \\
\hline "Chooser" & "Chosen" & Number of cases \\
\hline \multirow[t]{2}{*}{ Red ठ̆ } & IRed $Q$ & . 54 \\
\hline & White ? & 82 \\
\hline \multirow{2}{*}{ White ${ }^{\pi}$} & IRed 9 & 40 \\
\hline & : White $Q$ & 93 \\
\hline \multirow[t]{2}{*}{ Red $q$} & $\int \operatorname{Red} 0$ & 53 \\
\hline & Thite $0^{7}$ & 14 \\
\hline \multirow[t]{2}{*}{ White 9} & (Red $0^{\pi}$ & 62 \\
\hline & White $0^{\pi}$ & 19 \\
\hline
\end{tabular}




\section{TABLE IV-Continued}

Gray (normal) vs. yellow body color. (Red eyes.)

Gray 0

IGray + ?

IYellow 우

Yellow $0^{7}$

i Gray $O$

Yellow

iYellow 7

Gray $Q$

IGray of $^{7}$

30

Yellow $q$

iYellow $\overrightarrow{0}$

60

i Gray os

12

iYellow of

Vermilion

|Red-gray $0^{7}$

Black-yellow P

$$
\text { White-gray } \sigma
$$

Gray and yellow body colors. (White eyes.)

$\begin{array}{ll}\text { Gray } \sigma^{7} & \text { \{Gray } Q \\ \text { Gray } O & \text { Yellow } \\ & \text { \{ray } \sigma^{\gamma} \\ \text { Yellow } \sigma\end{array}$

Red and white eyes. (Yellow body color.)

Red 0

White $\sigma^{3}$

$\left\{\begin{array}{l}\text { Red } \text { P } \\ \text { White } 9\end{array}\right.$

$\{$ Red 9

White 9

Red $P$

Red 0

White $\overline{0}$

White 9

\section{Red 0}

i white of

Red and vermilion eyes. (Gray body color.)

Red $\sigma^{\top}$

Vermilion $\sigma^{\lambda}$

$\operatorname{Red}$ \%

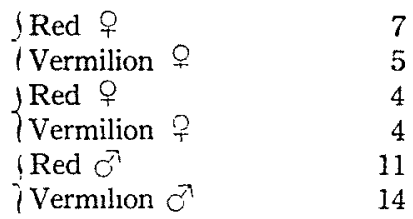

Long and curved wings. (Other characters normal.)

Long $d$

I Long o

I Curved 9

Curved $C^{-3}$

ILong $f$

iCurved 8

Long 9

$\left\{\right.$ Long $\sigma^{\lambda}$

$\{$ Curved 0

Curved 우
1 Long $\overrightarrow{0}$

i Curved 0 
It appears that sexual selection is not involved in any of these cases. The impression gained from observation of over 1.000 " contests" of this sort is that the outcome is not a matter of choice. A female, in the great majority of cases, seems to allow the first active amorous male that comes along to pair with her; or, if she is disinclined to mate, resists all males apparently indifferently. When a male is sexually excited he pairs with the first female he finds which will allow him to. As a result, the more active and vigorous males are likely to win their contests, and the greater the difference in vigor, the grcater the proportion of times the better male wins. This is just what the results show to happen. So far as the small numbers show, the vermilion male is at no disadvantage and the curved male is not quite able to hold his own, while it is certain that the yellow and white are far behind their normal opponents.

In the converse case, a less vigorous female will be less likely to resist or escape from the male successfully if she be disinclined to mate. But this influence should have less effect on the result than the one discussed above, since both females will often be willing to mate and will not try to escape. This again agrees exactly with the facts as given above.

The two results of unequal vigor discussed above seem to me quite adequate to explain all the results obtained. There is no evidence of any "choice" on the part either of males or of females. Unlike the abnormal venation studied by Lutz, these mutants probably have no significance from the point of view of sexual selection, in the narrower sense of that term.

\section{SUMMARY}

Experiments indicate that sight is not essential in sex recognition in Drosophlia. The olfactory and tactile senses are probably both concerned, as in most other insects.

The wings of the male play a conspicuous part in normal courtship. Experiments with males from which the wings had been removed indicated that the function of these organs in courtship is the production of sexual excitement in the femalc.

Experinents were carried out with four mutants (white eyes, vermilior eyes, yellow body color, and curved wings), involving the observation of 839 contested matings.

As a result of these experiments it seems probable that the 
four characters involved have no selective value, except in so far as results from the fact that at least two of these classes are less active then normals.

In general it is probable that, in Drosophila, neither sex exercises any "choice" in the selection of a mate. A female that is ready to mate will accept any male, and a male that is ready to mate will do so with the first female that will allow him to.

\section{LITERATURE CITED}

BARrows, W. M. The reactions of the pomace fly, Drosophila ampelophila, to 1907. odorous substances. Jour. Exper. Zool., IV.

BERLESE, A. L'accoppiamento della Mosca domestica Rev. Palol. Veg., IX. $190^{2}$. Chidester, F. E The matung habits of four species of the Brachyura. Biol. 1911. Bull., XXI.

DARWIN, C The descent of man and selection in relation to sex. 2nd edition. 1874.

FEDERLEY, H. Vererbungsstudien an der Lepidopteren-gattung Pygaera. Arch. 1911. Rass. u. Ges - Blo', VIII.

FíkÉ, C. Expériences relatives aux rapports homosexuels chez les hammetons. 1898. C. R. Soc. Biol, V.

1898a. Expériences relatives a l'mstinct sexuel chez le bombyx du murer. C. R. Soc. Biol., V.

HEweTT, C. G. Structure, development, and bionomics of the housefly. Quart. 1908. Jour Micr. Sci, LII.

HowarD, L. O. The insect book, New York. 1902.

KELLOGG, V. L. Some silkworm moth reflexes Biol. Bull., XII. 1907.

- Kirkiand, G H. Assembling of the gypsy moth Gypsy Moth Report. Mass. 1896. Board. Agr.

LuTz, F. E. Expertments with Drosophila ampelophila concerning evolution. 1911. Cannegue Inst. Wash. publ. 143.

MAsr, S. O. Behavior of fire-flies (Photinus pyralis) with special reference to 1912. the problem of orientation Jour. Antmal Behav., II.

Mayer, A. G. On the mating instinct in moths. Ann. Mag. Nat. H, V. 1900.

MAYer, A. G. and C. G. Soule. Some reactions of caterpillars and moths. Jour. 1906 Exper. Zool., III.

Morgan, T. H. Sex-limited inheritance in Drosophila. Sctence, XXXII 1910 1911. The origin of nine wing-mutations in Drosophila. Science, XXXIII. 1911a. The origin of five mutations in eye-color in Drosophila, etc. Science, XXXIII. 1913. Heredity and sex. New York.

PAYNE, F. Drosophila ampelophlla bred in the dark for sixty-nine generations. 1911. Biol. Bull., XXI.

PoultoN, E. B. Empidae and their prey in relation to courtship. Entrm. Mag., 1913. XXIV.

STOCKARD, C. R. Habits, reactions and mating instincts of the walking stick, 1908. Aplopus mayeri. Carnegie Inst. Wash. publ. 103.

TOWER, W. L. An investigation of evolution in Chrysomelid beetles of the genus 1906. Leptinotarsa. Carnegie Insl. Wash. publ. 48.

Washburn, M. F. The anmal mind. New York. 1909.

Watson, J, B. Behavior. New York. 1914 .

YULE, G. U. An introduction to the theory of statistics. London. 1911 . 